\title{
Application of therapeutic drug monitoring of imatinib for individual treatment of gastrointestinal stromal tumor
}

\author{
Koji Fukuda1, Kazuhiro Shimazu1, Taichi Yoshida1, Masahiro Inoue1, \\ Masatomo Miura², Hiroyuki Shibata1
}

\author{
${ }_{1}$ Department of Clinical Oncology, Graduate School of Medicine, Akita, Japan \\ ${ }^{2}$ Department of Pharmacy, University Hospital, Akita University, 010-8543 Hondo 1-1-1, Akita, Japan
}

Received February 7, 2016; Revised May 30, 2016; Accepted May 30, 2016; Published Online May 31, 2016

\section{Case Report}

\begin{abstract}
Many molecular target agents are continuously administered at fixed dosages. Imatinib, which can control the growth of a gastrointestinal stromal tumor, is administrated at $400 \mathrm{mg} /$ day. However, many patients cannot continue treatment because of adverse events, such as neutropenia. To obtain the best therapeutic response while maintaining quality of life, individualization should be considered. Study participants were gastrointestinal stromal tumor patients who required treatment with imatinib. Therapeutic drug monitoring was conducted using high-performance liquid chromatography. In our study, the trough (lowest) concentration that a drug reaches before the next dose is administered differed among patients. The grades of adverse events also differed individually. Moreover, the dosage that was necessary to shrink gastrointestinal stromal tumor differed in cases by cases. Dosage was modified according to the balance between blood concentration and therapeutic responses in order to minimize adverse events for individual patients, and to maximize the effect as the responses differed among patients. It was shown that based on therapeutic drug monitoring, individualization enabled the patients who may not normally continue the typical treatment to tolerate imatinib. According to the therapeutic drug monitoring, individualization of dosage of imatinib could improve the patients' outcomes in both ends, therapeutic and adeverse responses.
\end{abstract}

Keywords: Therapeutic drug monitoring; Imatinib; Gastrointestinal stromal tumor

\section{Introduction}

Individualization of cancer chemotherapy with cytotoxic agents for solid tumors is a very important issue. Dosage is practically decided using the individual body surface area of the patient in many cases. Continuation of treatment and/or adjustment of dosage are judged by the evaluation of therapeutic outcome and the grading of adverse events according to Response Evaluation Criteria in Solid Tumors (RECIST) and Common Terminology Criteria for Adverse Events (CTC-AE), respectively. Therapeutic drug monitoring (TDM) could offer helpful information related to cancer chemotherapy as well as the anti-microbial efficacy of antibiotics such as vancomycin ${ }^{1}$ or lithium salts ${ }^{2}$ for major depressive disorder ${ }^{1}$. Nonetheless, TDM of methotrexate is only covered by medical insurance as a cytotoxic agent. ${ }^{3}$ Many molecular targeted agents have been approved successively in the $21^{\text {st }}$ century. Some of these drugs are administered on the basis of the patients' weight, but many of them are given at a fixed dosage. Examples of such drugs include sorafenib for hepatocellular carcinoma ${ }^{4}$ and sunitinib for renal cell carcinoma 5 .

A gastrointestinal stromal tumor (GIST) is derived from the intestinal smooth muscle pacemaker cell, known as the Cajal cell; typically, it results from gain-of-function mutations in the KIT or platelet-derived growth factor receptor $\alpha$ (PDGFRA) genes. ${ }^{6}$ Imatinib is a tyrosine kinase inhibitor targeting KIT and PDGFRA proteins and is approved for advanced and post-operative patients, a high-risk group of GIST.7 Imatinib for GIST is administered at a fixed dosage of $400 \mathrm{mg}$ /day. Monthly TDM for imatinib has recently been covered by medical insurance in Japan. The blood concentration of imatinib is measured by liquid chromatography-tandem mass spectrometry $^{8}$ or high-performance liquid 
chromatography (HPLC) ${ }^{9}$. The purpose of TDM is to adjust the blood concentration of imatinib within the therapeutic window (TW). TW is the value between the minimal effective concentration (MEC) and the minimal toxic concentration (MTC). It is important to be aware of TW to minimize the adverse effects and maximize the therapeutic effect. Therefore, it is necessary to clarify the pharmacodynamics (PD) and pharmacokinetics (PK) of imatinib. However, the therapeutic effects and adverse events associated with imatinib differ among patients, and TW ought to be determined individually. We present a cohort, where individualization using TDM of imatinib was successfully applied for GIST. We consider further application of TDM for individualization through this group of individuals.

\section{Methods/Case Presentation}

The blood concentration of imatinib was examined using HPLC, as established by Miura. ${ }^{9}$ To detect the trough value $\left(\mathrm{C}_{\text {trough }}\right)$, samples were obtained in the morning before administration of imatinib. As the necessary volume for TDM is $0.3 \mathrm{~mL}$, a routine blood test is sufficient. Study participants were advanced or post-operative GIST patients who required treatment with imatinib and who visited the Department of Clinical Oncology, Akita University Hospital from August 2014 to December 2015. All participants agreed with this analysis and publication; written informed consent was obtained. Evaluation of the therapeutic response was conducted using RECIST, version 1.1. The grade of adverse events was judged using CTC-AE v4.0.

\section{Results}

We applied TDM of imatinib for 4 cases of GIST. Clinical characteristics and the therapeutic courses are summarized in Table 1.

Case 1 was a 41-year old female with operated gastric GIST, peritonitis carcinomatosa (PC) and liver metastasis. Liver metastasis could be controlled by radiofrequency ablation (RFA). Imatinib was administered at $400 \mathrm{mg} /$ day for PC. PC was controlled for 12 months, and there were no adverse events observed. The $C_{\text {trough }}$ values ranged from 1,960 to 2,120 ng/mL (Figure 1).

Table 1: Characters of the participants

\begin{tabular}{|c|c|c|c|c|c|c|c|c|}
\hline $\begin{array}{c}\text { Case } \\
\#\end{array}$ & $\begin{array}{l}\text { Sex } \\
\text { / Age }\end{array}$ & $\begin{array}{c}\text { Diagnosis } \\
\text { (primary) } \\
\text { (meta) }\end{array}$ & $\begin{array}{c}\text { KIT } \\
\text { Mutation }\end{array}$ & Treat & $\begin{array}{c}\text { Dosage } \\
\text { of ima } \\
\text { (mg) }\end{array}$ & $\begin{array}{c}\text { Best } \\
\text { Response }\end{array}$ & $\begin{array}{c}\mathrm{AE} \\
(\mathrm{Gr} 3)\end{array}$ & $\begin{array}{c}\mathrm{C}_{\text {trough }} \\
(\mathrm{ng} / \mathrm{mL})\end{array}$ \\
\hline 1 & $\begin{array}{l}\mathrm{F} \\
/ 41\end{array}$ & $\begin{array}{c}\text {-Gastric } \\
\text { •PC } \\
\text { • Liver }\end{array}$ & No (wild) & $\begin{array}{l}\text { - surg } \\
\text { - ima } \\
\text { - RFA }\end{array}$ & - 400 & -SD & No & $\begin{array}{l}-1,960 \\
-2,120\end{array}$ \\
\hline 2 & $\begin{array}{c}\mathrm{M} \\
/ 48\end{array}$ & $\begin{array}{c}\text {-Mesenteric } \\
\text { •PC (rec) }\end{array}$ & $\begin{array}{c}\text { Ex 9, } \\
\text { codon 504, } \\
\text { 6-bp } \\
\text { insertion }\end{array}$ & $\begin{array}{l}\text { - surg } \\
\text { /ima } \\
\text { - ima }\end{array}$ & - 400 & $\triangleright P R$ & No & $\begin{array}{l}-252 \\
-659\end{array}$ \\
\hline 3 & $\begin{array}{l}\mathrm{F} \\
/ 47\end{array}$ & -Gastric & ND & $\begin{array}{l}\text { - surg } \\
\text { - ima }\end{array}$ & $\begin{array}{l}\text { - } 400 \\
\text { - } 300\end{array}$ & ND & $\begin{array}{l}\text { - neu } \\
\text { - neu }\end{array}$ & $\begin{array}{l}\text { - } 785 \\
\text { - } 460\end{array}$ \\
\hline 4 & $\begin{array}{c}\mathrm{M} \\
/ 71\end{array}$ & $\begin{array}{c}\Rightarrow \text { Gastric } \\
\qquad \text { PC } \\
>\text { Liver }\end{array}$ & $\begin{array}{c}\text { Ex 11, } \\
\text { codon } \\
557 / 558 \\
\text { del } \\
\text { (in-frame) }\end{array}$ & $\begin{array}{l}\text { - surg } \\
\text { - ima } \\
\text { - RFA }\end{array}$ & $\begin{array}{l}\text { - } 300 \\
\text { - } 200 \\
\text { - } 100 \\
\text { - } 50^{*} \\
\text { - } \mathrm{Int}\end{array}$ & $\bullet P R$ & $\begin{array}{l}\text { neu } \\
\text { neu } \\
\text { No } \\
\text { No } \\
\text { neu }\end{array}$ & $\begin{array}{l}\text { > } 709 \\
\text { - } 565 \\
\text { - } 593 \\
\text { - } 54 \\
\text { - } 60 \\
-654\end{array}$ \\
\hline
\end{tabular}

F; female, M; male, PC; peritonitis carcinomatosa, Ex; Exon, Surg; surgery, ima; imatinib, RFA; radio frequency ablation, TTP; time to progression, AE; adverse event, ND; not determined, SD; stable disease, PR; partial response, neu; neutropenia, * $100 \mathrm{mg}$ of ima at every 2 day, Int; intermittent treatment 


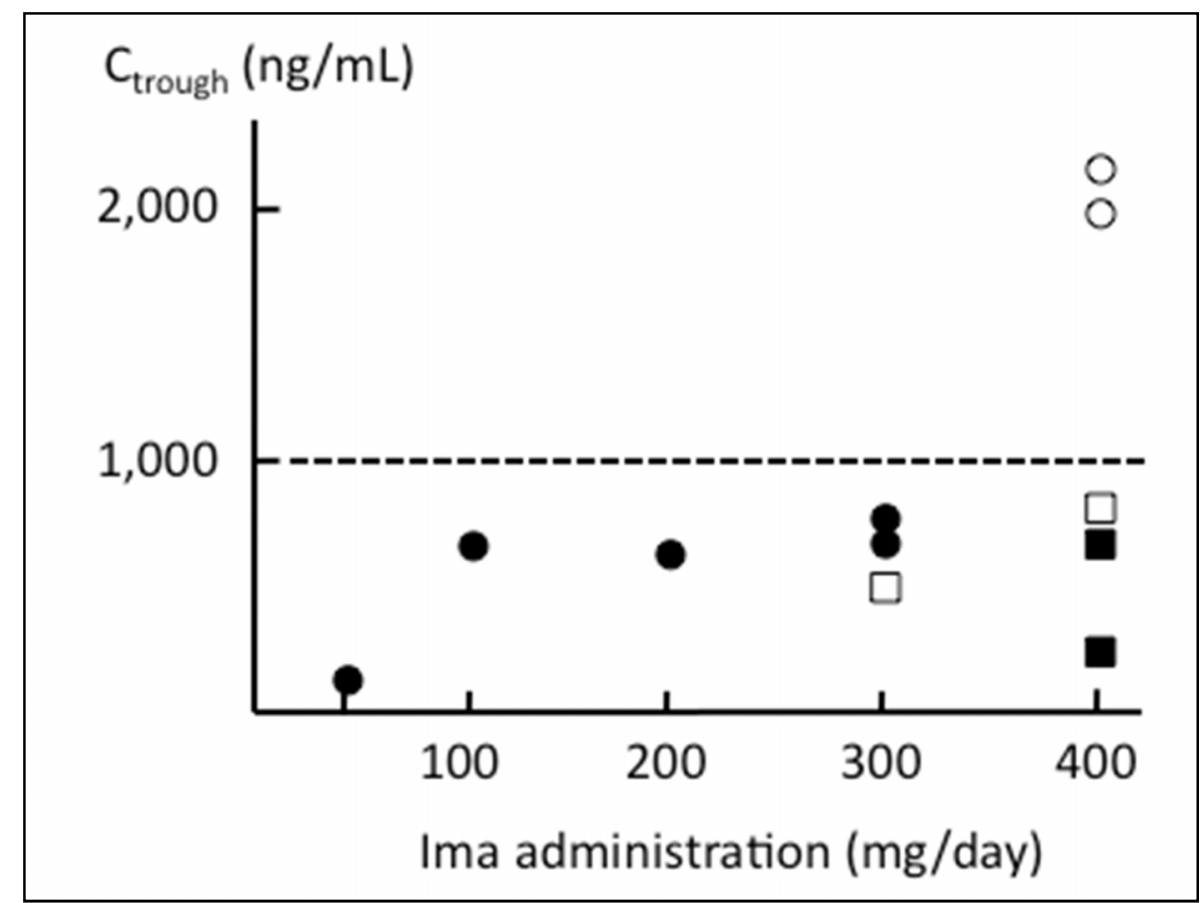

Figure 1: Correlation between imatinib administration dosage and the $\mathrm{C}_{\text {through }}$ level. Case 1 (open circle), Case 2 (closed rectangle), Case 3 (open rectangle) and Case 4 (closed circle)

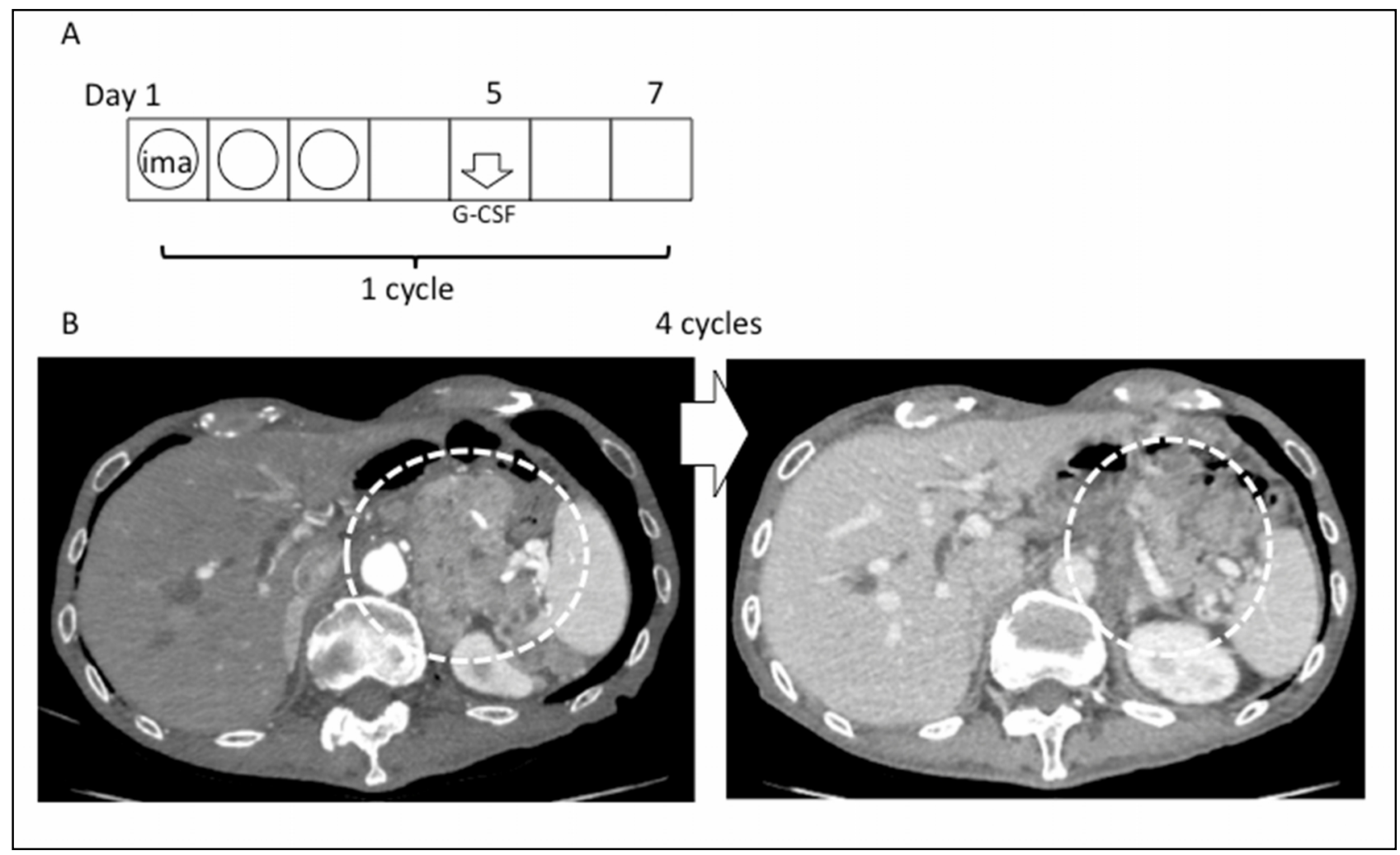

Figure 2: Intermittent administration with imatinib for treating Case 4. (A) Weekly treatment schedule. Ima; imatinib, G-CSF; granulocyte-colony stimulating factor; (B) Evaluation of the target lesion (PC nodules) by CT imaging 
Case 2 was a 48-year old male with resected mesenteric GIST. After completion of adjuvant chemotherapy with imatinib, PC nodules recurred. Administration of imatinib at $400 \mathrm{mg} /$ day could control the PC nodules for 10 months. The best response observed was a partial response. No adverse events were observed. The $\mathrm{C}_{\text {trough }}$ values ranged from 252 to $659 \mathrm{ng} / \mathrm{mL}$ (Figure 1).

Case 3 was a 47-year old female with resected gastric GIST, considered high-risk. Adjuvant chemotherapy with imatinib was started, but a dose of $400 \mathrm{mg} /$ day could not be continued because of the frequent occurrence of grade 3 neutropenia. Consequently, the dosage was reduced to $300 \mathrm{mg} /$ day. This dosage was better-tolerated despite occasional grade 3 neutropenia.

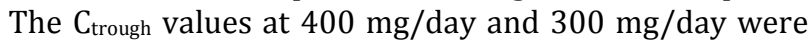
785 and $460 \mathrm{ng} / \mathrm{mL}$, respectively (Figure 1). During 24 months of this regimen, no recurrences were apparent.

Case 4 was a 71-year old male with recurrence of liver metastasis after resected distal gastric GIST. He was referred from another hospital due to imatinib treatment difficulties caused by frequent neutropenia. First, imatinib was started at a dosage of $300 \mathrm{mg} /$ day to confirm sensitivity of imatinib against liver metastasis. Positron emission tomography-computed tomography (PET-CT) indicated the disappearance of ${ }^{18}$ fluorodeoxy glucose uptake in the liver, 41 days after initiation of imatinib (before treatment; SUV $\max =3.9-4.1$ ). However, at day 23, grade 3 neutropenia became apparent and was prolonged. Consequently, we reduced the dosage on a step-by-step gradient to 200 and to 100 $\mathrm{mg} /$ day, but the patient continued to experience grade 3 neutropenia. In this case, the $C_{\text {trough }}$ levels were not decreased and linear. The values were 709, 565 and 593 $\mathrm{ng} / \mathrm{mL}$ at 300, 200 and $100 \mathrm{mg} /$ day administration, respectively (Figure 1). Furthermore, when imatinib was administered at $100 \mathrm{mg}$ every two days, the $\mathrm{C}_{\text {trough }}$ level was reduced to $54 \mathrm{ng} / \mathrm{mL}$. We found that one-day interruption reduced the blood concentration below 10 $\%$ of the $\mathrm{C}_{\text {trough }}$ level.

As the administration of imatinib was difficult and the target lesion existed only in the liver, we selected RFA for the liver metastasis. RFA could control the liver targets, but 2.5 months after RFA, gastrointestinal obstruction occurred due to an intra-abdominal disseminated tumor ( $6 \mathrm{~cm}$ in diameter at its largest size) near the esophageal-cardiac junction. Therefore, we decided to intermittently treat this situation with imatinib. As $300 \mathrm{mg} /$ day of imatinib was effective, imatinib was administered for 3 successive days and was stopped from day 4 to day 7 . The $C_{\text {trough }}$ level at day 4 was $654 \mathrm{ng} / \mathrm{mL}$ and at day $8 \mathrm{had}$ reduced to $60 \mathrm{ng} / \mathrm{mL}$ (Figure 1).

However, as neutropenia was still present, granulocyte-colony stimulating factor was administered on day 5 . We proposed this intermittent treatment to the patient and obtained informed consent (Figure 2). Gastrointestinal obstruction improved at day 7 after initiation of intermittent treatment, and an approximate $50 \%$ reduction was confirmed by CT a month after initiation. This treatment was continued without any adverse events, and he still has partial response at 9.5 months.

\section{Discussion}

The $C_{\text {through }}$ level of imatinib ranges from 414 to 4,182 $\mathrm{ng} / \mathrm{mL}$ at a dosage of $400 \mathrm{mg} /$ day. $^{10}$ In our study participants, this value ranged from 252 to $2,120 \mathrm{ng} / \mathrm{mL}$. These data indicate that PK of imatinib differs among individuals. It is recommended that the target concentration of imatinib for GIST was more than 1,100 $\mathrm{ng} / \mathrm{mL}\left(\mathrm{C}_{\text {trough }}\right){ }^{11}$ However, the therapeutic response was observed at levels below $1,000 \mathrm{ng} / \mathrm{mL}$ in some other studies as well as in ours. Furthermore, the grade of adverse events differed from patient to patient using the same dosage. These facts indicated that PD of imatinib also differs between patients. Consequently, the validation of individual TW of imatinib is very difficult. ${ }^{12}$ There might be influential factors affecting TW. For example, breast cancer resistance protein (BCRP) contributes to the excretion of imatinib metabolites to the bile duct.13 A BCRP gene (421 C>A) single nucleotide polymorphism, which is found in approximately $45 \%$ of the normal Japanese population ${ }^{14}$, reduces BCRP function ${ }^{15}$. Consequently, the concentration of imatinib in patients bearing this mutation might increase. In addition, the effect of imatinib on GIST itself depends on KIT or PDGFRA mutations. ${ }^{16}$ Besides these examples, there might be other unknown factors that can affect the therapeutic effects and/or the adverse events of imatinib. ${ }^{12}$ The correlation between the $C_{\text {through }}$ level and the therapeutic effect and/or the correlation between the $\mathrm{C}_{\text {through }}$ level and the adverse event should be monitored using TDM. This would optimize the effects of imatinib. Accordingly, we suggest individualization of the drug dosage.

\section{Conclusion}

Therapeutic drug monitoring of imatinib for GIST is informative and beneficial method to the patients who cannot continue the treatment due to the adverse events by measuring of the individual therapeutic window of imatinib.

\section{Conflict of interest}

The authors declare that they have no conflicts of interest. The authors alone are responsible for the content and writing of the paper. 


\section{References}

1. Ye ZK, Li C and Zhai SD. Guidelines for therapeutic drug monitoring of vancomycin: a systematic review. PLoS One. 2014; 9: e99044.

2. Deligiannidis KM, Byatt N and Freeman MP. Pharmacotherapy for mood disorders in pregnancy: a review of pharmacokinetic changes and clinical recommendations for therapeutic drug monitoring. J Clin Psychopharmacol. 2014;34(2): 244-55.

3. Paci A, Veal G, Bardin C, et al. Review of therapeutic drug monitoring of anticancer drugs part 1--cytotoxics. Eur J Cancer. 2014;50(12): 2010-9.

4. Stotz M, Gerger A, Haybaeck J, et al. Molecular Targeted Therapies in Hepatocellular Carcinoma: Past, Present and Future. Anticancer Res. 2015;35(11): 5737-44.

5. Minguet J, Smith KH, Bramlage CP, et al. Targeted therapies for treatment of renal cell carcinoma: recent advances and future perspectives. Cancer Chemother Pharmacol. 2015;76(2): 219-33.

6. Miettinen M and Lasota J. Gastrointestinal stromal tumors: review on morphology, molecular pathology, prognosis, and differential diagnosis. Arch Pathol Lab Med. 2006;130(10): 1466-78.

7. Lopes LF and Bacchi CE. Imatinib treatment for gastrointestinal stromal tumour (GIST). J Cell Mol Med. 2010;14(1-2): 42-50.

8. Bakhtiar R, Lohne J, Ramos L, et al. High-throughput quantification of the anti-leukemia drug STI571 (Gleevec) and its main metabolite (CGP 74588) in human plasma using liquid chromatography-tandem mass spectrometry. Analyt Technol Biomed Life Sci. 2002;768(2): 325-40.
9. Miura M, Takahashi N and Sawada K. Quantitative determination of imatinib in human plasma with high-performance liquid chromatography and ultraviolet detection. J Chromatogr Sci. 2011;49(5): 412-5.

10. Demetri GD, Wang Y, Wehrle E, et al. Imatinib plasma levels are correlated with clinical benefit in patients with unresectable/metastatic gastrointestinal stromal tumors. J Clin Oncol. 2009;27(19): 3141-7.

11. Yu H, Steeghs N, Nijenhuis CM, et al. Practical guidelines for therapeutic drug monitoring of anticancer tyrosine kinase inhibitors: focus on the pharmacokinetic targets. Clin Pharmacokinet. 2014;53(4): 305-25.

12. Klümpen HJ, Samer CF, Mathijssen RH, et al. Moving towards dose individualization of tyrosine kinase inhibitors. Cancer Treat Rev. 2011;37(4): 251-60.

13. Oostendorp RL, Buckle T, Beijnen JH, et al. The effect of P-gp (Mdr1a/1b), BCRP (Bcrp1) and $\mathrm{P}$-gp/BCRP inhibitors on the in vivo absorption, distribution, metabolism and excretion of imatinib. Invest New Drugs. 2009;27(1): 31-40.

14. Noguchi K, Katayama K and Sugimoto Y. Human ABC transporter ABCG2/BCRP expression in chemoresistance: basic and clinical perspectives for molecular cancer therapeutics. Pharmgenomics Pers Med. 2014;7: 53-64.

15. Urquhart BL, Ware JA, Tirona RG, et al. Breast cancer resistance protein (ABCG2) and drug disposition: intestinal expression, polymorphisms and sulfasalazine as an in vivo probe. Pharmacogenet Genomics. 2008;18(5): 439-48.

16. Lee JH, Kim Y, Choi JW, et al. Correlation of imatinib resistance with the mutational status of KIT and PDGFRA genes in gastrointestinal stromal tumors: a meta-analysis. J Gastrointestin Liver Dis. 2013;22(4): 413-8. 